\title{
Comparison of Patterns of Genetic Variation and Demographic History in the Greater Sage-Grouse (Centrocercus urophasianus): Relevance for Conservation
}

\author{
Robert M. Zink ${ }^{*}$ \\ Bell Museum and Department of Ecology, Evolution and Behavior, University of Minnesota, St. Paul, MN, 55108, USA
}

\begin{abstract}
The greater sage-grouse (Centrocercus urophasianus) was once widespread in western North America but its range has contracted by an uncertain degree owing to anthropogenic and natural causes. Concern over population declines has led to its proposed listing as threatened under the U.S. Endangered Species Act. Detailed genetic and demographic analyses of this species throughout its range are available but heretofore have not been compared. Reduced genetic variability is often taken as a proxy for declining populations, but rarely are there quantitative population estimates with which to compare. I compared published mitochondrial DNA (mtDNA) control region sequences, microsatellite allele frequencies at seven loci, and estimates of numbers of males per lek, number of active leks, percent decline in the best population models, and the probability $(\mathrm{P})$ of $\mathrm{Ne}<50$ in 30 years and $\mathrm{P}(\mathrm{Ne}<500)$ in 100 years, at two spatial scales, 45 local population samples and 16 larger aggregates of samples. When excluding the populations from the Columbia Basin, which show little genetic diversity and are statistical outliers, there were no consistent relationships between estimates of genetic variation and demographic trends across the remainder of the range at either spatial scale. A measure of inbreeding derived from microsatellite data was also not related to population trends. Thus, despite habitat reduction and range fragmentation, the greater sage-grouse does not exhibit expected genetic signatures of declining populations. Possibly, the mtDNA and microsatellite data are insufficiently sensitive to detect population declines that have occurred over the span of a half century. Alternatively, only when populations are reduced to the levels seen in the Columbia Basin will genetic effects be seen, suggesting that the bulk of the range of the greater sage-grouse is not currently in genetic peril.
\end{abstract}

Keywords: Conservation genetics, heterozygosity, inbreeding, microsatellite loci, mitochondrial DNA, population management, population structure.

\section{INTRODUCTION}

Many sources of biological information can guide management of threatened and endangered species. Measures of genetic variability and differentiation provide indirect historical information on whether populations have experienced bottlenecks or inbreeding, or have been isolated from exchanging individuals with other populations. Measures of demographic fluctuations through long-term population monitoring provide evidence on more recent population fluctuations. In theory, these two types of information should be complementary. Lower than average levels of genetic variability are typically inferred to be a result of population declines. Oyler-McCance et al. [1: p. 1293] noted that such populations "can suffer from inbreeding effects and can be more susceptible to parasitic agents and disease." Small populations can lose genetic diversity, which could hamper their ability to respond to new (or current) environmental challenges [2]. Furthermore, slightly deleterious alleles might increase in frequency and result in lower individual fitness. Given the potential for genetic and demographic information jointly to inform conservation efforts, it is

*Address correspondence to this author at the Bell Museum and Department of Ecology, Evolution and Behavior, University of Minnesota, St. Paul, MN, 55108, USA; Tel: 612624 7207; Fax: 612624 6777;

Email: zinkx003@umn.edu surprisingly rare to be able to compare measures of genetic variation and inbreeding depression with quantitative estimates of demographic history, especially for species of conservation concern.

The greater sage-grouse (Centrocercus urophasianus), considered threatened (but precluded) under the U.S. Endangered Species Act [3], is an exception. Garton et al. [4] provided a detailed demographic study of greater sage-grouse population trends at two geographic levels, a broad, inclusive level that included the seven sage grouse management zones (SMZ, Fig. 1), and 30 smaller population units within these zones. Using data from 1965 to 2007 (in five-year intervals) on the number of active leks (display grounds) and males per active lek, they computed estimates of population trends, and estimated the probability of population persistence $(\mathrm{P})$ at two levels $(\mathrm{Ne}<50,500) 30$ and 100 years into the future. $\mathrm{Ne}$ refers to the genetic effective population size, which is a function of how males and females contribute to future generations, and not an estimate of the census size of a population. They concluded that some populations are in danger of falling below the putative minimum viable population sizes or 50 or 500 , which some consider arbitrary [5]. This makes it appropriate to survey genetic variation to determine if populations estimated to be on downward trajectories also show reductions in levels of genetic diversity. 


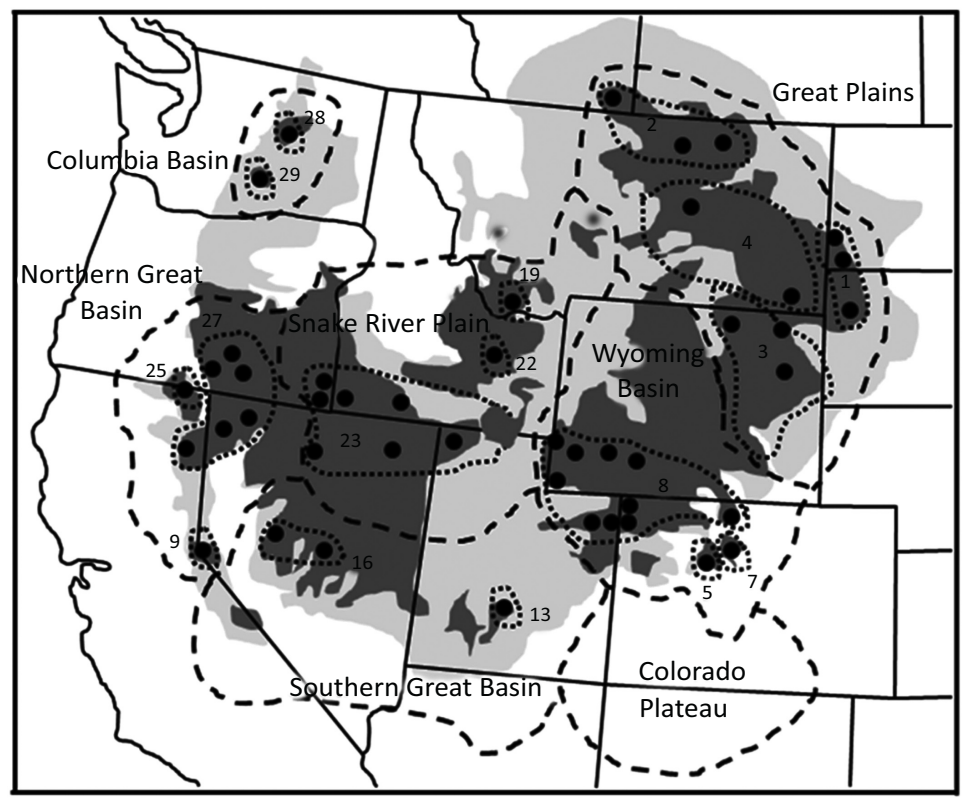

Fig. (1). Plot of sample sites (blackened circles) for genetic samples [1]. Dashed lines indicate greater sage-grouse Management Zones, and dotted lines indicate population samples from [4]. Numbers correspond to sequence of populations in [4]. Dark gray indicates current distribution and light gray indicates estimate of historical distribution.

Oyler-McCance et al. [1] surveyed mitochondrial DNA control region (141 base pairs) variation and genotyped seven microsatellite loci for over 1000 greater sage-grouse from 45 populations (Fig. 1) throughout the same area as that analyzed by Garton et al. [4]. They provided measures of genetic variation within populations, and genetic differentiation among the same populations for which Garton et al. [4] tallied the number of active leks and number of males per individual populations. In addition Oyler-McCance et al.'s [1] genetic data can be summarized for six of the seven SMZs (only the Colorado Plateau was missing), and for 16 of the 30 larger populations for which Garton et al. [4] provided measures of long-term demographic fluctuations and $\mathrm{P}(\mathrm{Ne}<50 ; \mathrm{Ne}<500)$. In this paper I compare genetic variability measures with quantitative estimates of population trends to determine whether the effects of population declines can be observed at two geographic scales in the microsatellite and mitochondrial DNA data for this species of conservation concern. The available data sets also allow comparison of the extent to which mtDNA and microsatellites provide similar estimates of population genetic variability.

\section{MATERIAL AND METHODOLOGY}

Analyses were performed on two data sets. Data set I consisted of 45 population samples, each of which has microsatellite and mtDNA data [1] and data on the number of active leks and number of males/active lek [4]. Data set II included the 16 population groupings for which Garton et al. [4] estimated $\mathrm{P}(\mathrm{Ne}<50$ or $\mathrm{Ne}<500)$ in the next 30 or 100 $\mathrm{yr}$, and for which mtDNA and microsatellite data were available. In addition, I used the percent population change in Garton et al.'s [4] "best model" as a measure of population fluctuation. Populations for which Garton et al. [4] did not find a significant overall trend were considered stable over the time period. For both data sets, if the relationship between the number of individuals sampled and measures of genetic variability were significantly correlated, residuals from linear regression were used in place of actual values (no differences were found using residuals from other regression models).

For data set II I regrouped individuals' mtDNA and microsatellite data and recomputed measures of genetic variability using Arlequin 3.5.1.3 [6]. Arlequin was also used to compute the Garza-Williamson [7] index (and a modified version) for both data sets (e.g., 16 and 45 population units), which compares the number of alleles at loci with the allelic range to provide an indication of whether populations exhibit effects of bottlenecks. I performed analyses with and without the samples from Yakima and Douglass/Grant (Moses Coulee, WA) representing the Columbia Basin, owing to the possibility that the low variation in these samples represents outliers that could bias analyses.

To evaluate the relationship among the variables, I computed a matrix of Pearson product-moment correlation coefficients. The computation of multiple coefficients runs the risk of spurious significance values. A standard approach is to apply a Bonferroni correction [8] that results in an experiment-wide lowering of the alpha level accepted for significance. For data set I, the level would be $0.05 / 21(0.0024)$ and for data set II, 0.05/45 (0.0011). Many authors $[9,10]$ have pointed out that this is extremely conservative and runs the opposite risk of failing to recognize significant values, especially if the relationship is weak but nonetheless significant and in studies with relatively small sample sizes. Because this is one of the first large-scale comparisons of genetic and demographic data, and is partly exploratory in nature, I assessed statistical significance using the standard of $P<0.05$, but it should be realized that some values are insignificant if the Bonferroni criterion is applied. Of course if a standard $P$-value is not significant, the Bonferroni correction is irrelevant. In addition, although comparisons among genetic variables or among demographic variables are likely 
non-independent, comparisons between these two classes of variables are less so. For example, in data set I, there are eight comparisons between genetic and demographic variables, and one could consider the appropriate Bonferroni correction to be $0.05 / 8$ or 0.0063 .

To determine whether one might expect a genetic signature of population reductions, I constructed 10 random samples from the total pool of individuals with microsatellite data that matched the observed sample size for each of the 45 populations in Oyler-McCance et al. [1], and plotted the relationship between number of individuals and average number of alleles/locus. If there were no relationship, it would suggest there was not enough variability among samples to detect effects from demographic fluctuations.

Previous genetic analyses $[1,11,12]$ documented the existence of two well-separated mtDNA clades that are currently geographically co-distributed over much of the range. To evaluate whether these might have once been allopatric and secondarily sympatric, and to provide historical perspective on the distribution and range displacements of greater sage-grouse, I computed ecological niche models for the present, Last Glacial Maximum (LGM; 21,000 ybp), and Last interglacial (LIG; 120,000 ybp). Locality records (n = 173) were obtained from Ornis2 (http://ornis2.ornisnet.org/); duplicate records (those $<1 \mathrm{~km}$ apart) were eliminated. Correlative ecological niche models $[13,14]$ were constructed using MAXENT ver 3.2.2 [15] for the present and projected to the LGM (CCSM database). Climatic data (19 layers) were obtained from the Worldclim bioclimatic database [16], and trimmed so as to provide a buffer around the species' range. Multiple methods exist to account for correlations among climate variables, none with clear superiority [17]. Based on an initial MAXENT run, climatic layers that contributed $5 \%$ or more to the model were chosen (layers 1238 111318 ) and MAXENT was rerun using these layers and all locality records for final maps. Each map was based on the average of five MAXENT runs (using all points) and plotted using DIVA-GIS ver. 7.1.7.2 [18]. Predicted distribution maps were coded as presence/absence using the logistic threshold for equal training sensitivity and specificity produced by MAXENT (value $=0.375$ ). MAXENT outputs a threshold-independent measure of the overall performance of the model (Area Under the Receiver Operating Curve or AUC). An AUC value of 0.5 indicates the predictive model is no better than random, whereas higher AUC values indicate better predictive ability with a value of 1 indicating perfect prediction. MAXENT's auto-features and the default regularization multiplier parameter (1.0) were used, and the number of iterations was increased to 1500 to allow the program to reach the default convergence threshold.

To explore further the recent evolutionary history of the two mtDNA clades of greater sage-grouse, DnaSP [19] was used to compute a mismatch distribution and associated statistics ( $\mathrm{k}$, average number of haplotypes; $\pi$, nucleotide diversity; h, haplotype diversity) independently for each clade.

\section{RESULTS}

\section{Data Set I (45 Populations)}

None of the measures of genetic variability (Table 1, Fig. S1) were significantly $(P>0.05)$ correlated with number of individuals per sample (Table 2). Measures of genetic variability were significant correlated for each type of genetic data, heterozygosity and number of alleles/locus $(P<0.001)$ for microsatellites, and haplotype and nucleotide diversity $(P<0.001)$ for the mtDNA data. Several measures of variability at microsatellite loci and mtDNA were significantly correlated, number of alleles/locus and haplotype diversity $(P=0.017)$, number of alleles/locus and nucleotide diversity $(P=0.05)$, heterozygosity and nucleotide diversity $(P<0.024)$, and heterozygosity and haplotype diversity $(P<0.001)$. There were no consistent or significant relationships between numbers of active leks, number of males/active lek, and heterozygosity, alleles/locus, mtDNA haplotype and nucleotide diversity (Fig. S1). Although microsatellite heterozygosity was significantly $(P=0.0395)$ correlated with the number of active leks, this relationship does not remain $(P=0.10)$ when the two samples from the Columbia Basin are omitted. The G-W index was not significantly $(P>0.05)$ related to measures of population size (Fig. 2).

\section{Data Set II (16 Populations)}

Only the average number of alleles/locus was significantly correlated $(P<0.001)$ with number of individuals per sample, hence, residuals from the regression of these two variables were used subsequently (Table 3). Measures of genetic variability were significant correlated for each type of genetic data, heterozygosity and number of alleles/locus $(P=0.007)$ for microsatellites, and nucleotide and haplotype diversity for the mtDNA data $(P<0.001)$ (Table 4). Heterozygosity was correlated with haplotype diversity $(P=0.013)$, and number of alleles/locus was correlated with haplotype $(P=0.019)$ and nucleotide $(P=0.013)$ diversity. When the two samples from the Columbia Basin were omitted, no significant correlations remained. With one exception, no correlations were significant between measures of genetic variability and percent decline in best model, $\mathrm{P}(\mathrm{Ne})$ $<50$ in 30 years or $\mathrm{P}(\mathrm{Ne})<500$ in 100 years (Figs. 3-4). The $\mathrm{G}-\mathrm{W}$ index was not significantly $(\mathrm{P}>0.05)$ related to measures of population trends (Fig. 5). Interestingly, there were no significant correlations between percent decline in best model, $\mathrm{P}(\mathrm{Ne})<50$ in $30 \mathrm{yrs}$, and $\mathrm{P}(\mathrm{Ne})<500$ in $100 \mathrm{yrs}$ (Table 4). Random samples of microsatellite genotypes showed that the average number of alleles/locus varied from 6 to 12 (Fig. S2), suggesting that this genetic measure has the potential to reveal demographic declines.

\section{Ecological Niche Models}

Predicted current distribution agrees with the known historical distribution (Fig. 6) and the LIG predicted distribution (not shown); the AUC score of 0.947 estimated under current climate conditions indicates a very good ability to discriminate between presence and absence locations. The LGM distribution suggests two potential refugia, one in the southeast and the consisting of the remainder of the range. Although there is southward displacement at the LGM, much of the distribution, especially in the west, is similar to that found today, suggesting that the species was not greatly range-restricted especially in the western part of the range, at the LGM. 
Table 1. Population samples, greater sage-grouse Management (SMZ) zones, number of active leks, number of males per active lek and measures of genetic variability at 7 microsatellite loci and mtDNA control region for 45 population samples ${ }^{1}[1,4]$.

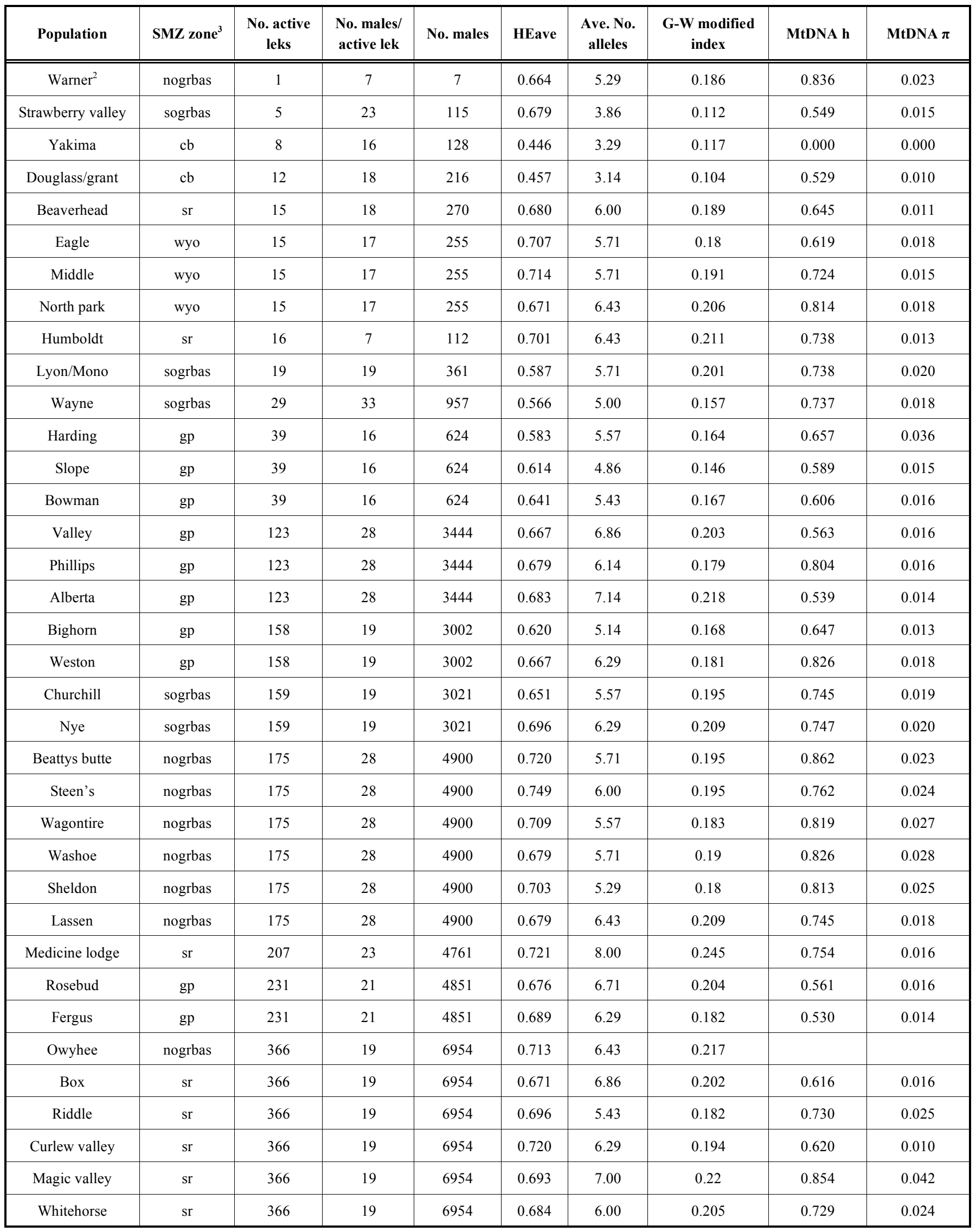


(Table 1) contd....

\begin{tabular}{|c|c|c|c|c|c|c|c|c|c|}
\hline Population & SMZ zone & $\begin{array}{c}\text { No. active } \\
\text { leks }\end{array}$ & $\begin{array}{c}\text { No. males/ } \\
\text { active lek }\end{array}$ & No. males & HEave & $\begin{array}{c}\text { Ave. No. } \\
\text { alleles }\end{array}$ & $\begin{array}{c}\text { G-W modified } \\
\text { index }\end{array}$ & MtDNA h & MtDNA $\pi$ \\
\hline \hline Elko & sr & 366 & 19 & 6954 & 0.754 & 7.00 & 0.225 & 0.863 & 0.039 \\
\hline Blue Mtn CO & wyo & 807 & 33 & 26631 & 0.690 & 5.71 & 0.184 & 0.667 & 0.015 \\
\hline Cold springs & wyo & 807 & 33 & 26631 & 0.693 & 6.14 & 0.201 & 0.707 & 0.017 \\
\hline Rich & wyo & 807 & 33 & 26631 & 0.693 & 6.71 & 0.209 & 0.801 & 0.020 \\
\hline Diamond & wyo & 807 & 33 & 26631 & 0.690 & 6.00 & 0.19 & 0.769 & 0.018 \\
\hline Blue Mt - UT & wyo & 807 & 33 & 26631 & 0.576 & 4.86 & 0.154 & 0.614 & 0.013 \\
\hline Kemmerer & wyo & 807 & 33 & 26631 & 0.703 & 5.71 & 0.186 & 0.732 & 0.017 \\
\hline Farson & wyo & 807 & 33 & 26631 & 0.716 & 6.00 & 0.188 & 0.637 & 0.014 \\
\hline Rawlins & wyo & 807 & 33 & 26631 & 0.749 & 6.71 & 0.218 & 0.626 & 0.012 \\
\hline
\end{tabular}

'Oyler-McCance et al. [1] show a locality "Owyhee, OR" on their Figure 5 that was not represented in their genetic data. Their locality point for "Weston WY" is actually for "Converse, WY" and there is no locality point for Weston, WY on their Figure 5.

${ }^{2}$ Although Garton et al.[4] list one lek with seven males, Oyler-McCance et al. [1] anlayzed 19 individuals for mtDNA and 22 individuals for the seven microsatellite loci, presumably as a result of sampling over years.

${ }^{3}$ nogrbas $=$ Northern Great Basin, sogrbas $=$ Southern Great Basin, $\mathrm{cb}=$ Columbia Basin, $\mathrm{sr}=$ Snake River Plain, wyo $=$ Wyoming Basin, $\mathrm{gp}=\mathrm{Great}$ Plains.

Table 2. Correlations among genetic [1] and demographic parameters [4] for 45 populations of greater sage-grouse. Asterisks indicate standard statistical significance levels $(* P<0.05, * * P<0.01, * * * P<0.001)$; see text for significance levels if applying Bonferroni corrections.

\begin{tabular}{|c|c|c|c|c|c|c|c|}
\hline & $\begin{array}{l}\text { No. active } \\
\text { leks }\end{array}$ & $\begin{array}{c}\text { No. males/active } \\
\text { lek }\end{array}$ & $\begin{array}{c}\text { No. } \\
\text { males }\end{array}$ & $\begin{array}{l}\text { Heterozygosity } \\
\text { (ave) }\end{array}$ & $\begin{array}{c}\text { Number } \\
\text { alleles/locus (ave) }\end{array}$ & MtDNA $h$ & MtDNA $\pi$ \\
\hline No. males/active lek & $0.68 * *$ & & & & & & \\
\hline No. males & $0.98 * *$ & $0.72 * *$ & & & & & \\
\hline Heterozygosity (ave) & $0.31 *$ & 0.21 & 0.26 & & & & \\
\hline MtDNA h & 0.12 & 0.13 & 0.09 & $0.59 * *$ & $0.45^{* *}$ & & \\
\hline MtDNA $\pi$ & 0.01 & -0.03 & -0.07 & $0.39 *$ & $0.30 *$ & $0.66^{* *}$ & \\
\hline
\end{tabular}

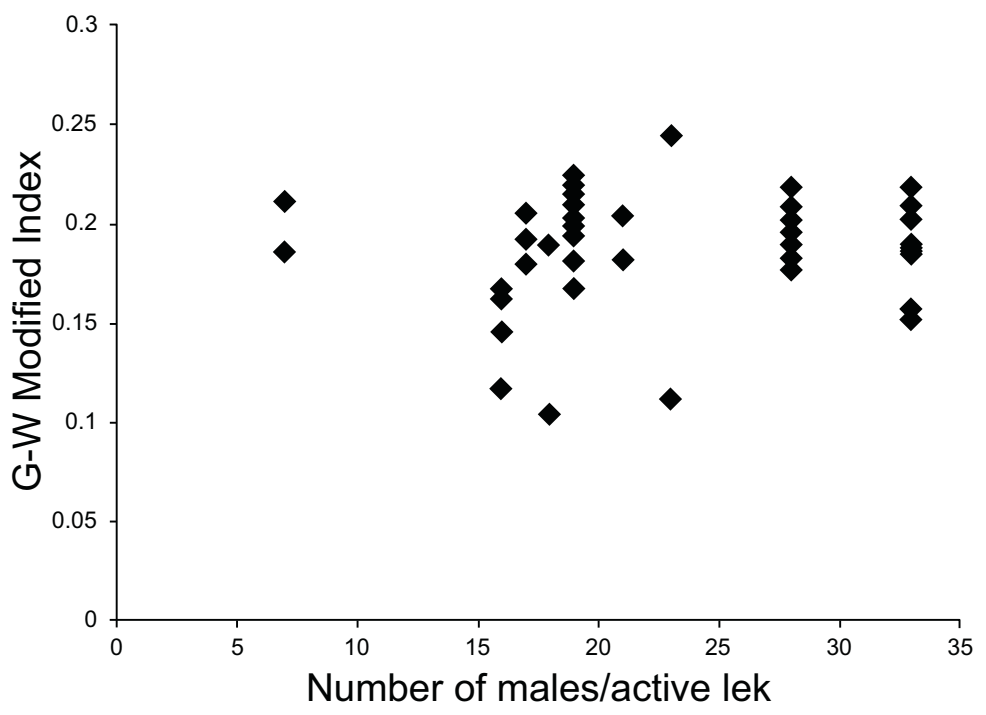

Fig. (2). Plot of Garza-Williamson inbreeding index [7] versus number of males per active lek [4] in greater sage-grouse, showing a lack of a relationship. 
Table 3. Demographic [4] and genetic [1] data for 16 population units of greater sage-grouse.

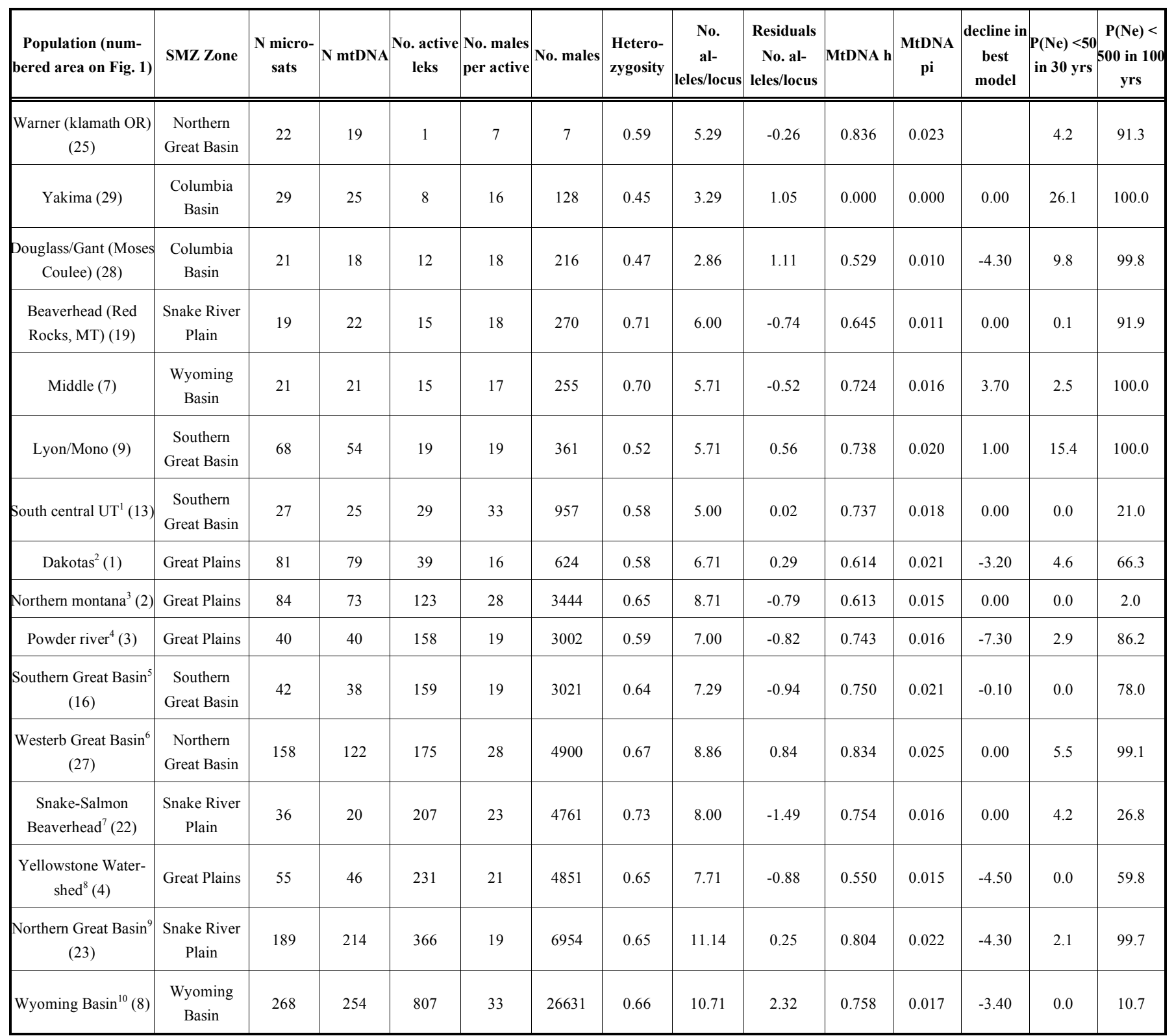

Locations within major populations from Oyler-McCance et al. (2005): ${ }^{1}$ Wayne; ${ }^{2}$ Harding, Slope, Bowman; ${ }^{3}$ Valley, Phillips, Alberta; ${ }^{4}$ Bighorn, Weston; ${ }^{5} \mathrm{Churchill}$, Nye; ${ }^{6} \mathrm{Beattys}$ Butte, Steens, Wagontire, Washoe, Sheldon, Lassen; ${ }^{7}$ Medicine Lodge; ${ }^{8}$ Rosebud, Fergus; ${ }^{9}$ Box Elder, Riddle, Curlew Valley, Magic Valley, Whitehorse, Elko, Humboldt; ${ }^{10}$ Blue Mountain CO, Cold Springs, Rich, Diamond, Blue Mountain UT, Kemmerer, Farson, Rawlins, North Park, Eagle, Strawberry.

\section{Recent Evolutionary History of Greater Sage-Grouse}

Clades I and II exhibit different mismatch distributions (Fig. 7) and Clade I was consistently less variable (Clade I: $\mathrm{k}=1.62, \pi=0.0129, \mathrm{~h}=0.76$; Clade II: $\mathrm{k}=2.52, \pi=0.019$, $\mathrm{h}=0.84)$. There is no evidence of two clades in the microsatellite data. However, because of the mode of inheritance of these bi-parental, nuclear markers, evidence of two clades would be erased with recombination and interbreeding.

\section{DISCUSSION}

Based on analyses of lek counts over several decades, greater sage-grouse have declined over much of their range [20], although the exact nature of the decline is unclear. Most assessments suggest population declines of from
$17-47 \%$ [21]. Connelly et al. [22] concluded from lek counts that the population declined by $2.0 \%$ per year from 1965 to 2003, and Schroeder et al. [23] suggested that the species currently occupies $56 \%$ of its pre-European settlement distribution. Given the lack of quantitative historical surveys that can be compared to current quantitative censuses, these estimates of range contraction are educated guesses. Nonetheless, it appears that not all regions have decreased to the same level, and some populations appear to be stable or increasing. The variability in degree of decline provides an opportunity for assessing the congruence of estimates of population trends and genetic variation. Oyler-McCance and Quinn [24] noted that estimates of population structure and gene flow in greater sage-grouse, i.e., connectivity of populations, as well as levels of genetic diversity "are paramount 
Table 4. Correlations among demographic and genetic variables for the 16 population units of greater sage-grouse described in [4]. Values in parentheses are for correlation coefficients excluding the two Columbia Basin populations. Asterisks indicate standard statistical significance levels $(* \mathbf{P}<0.05, * * \mathbf{P}<0.01, * * * \mathbf{P}<0.001)$; see text for significance levels if applying Bonferroni corrections.

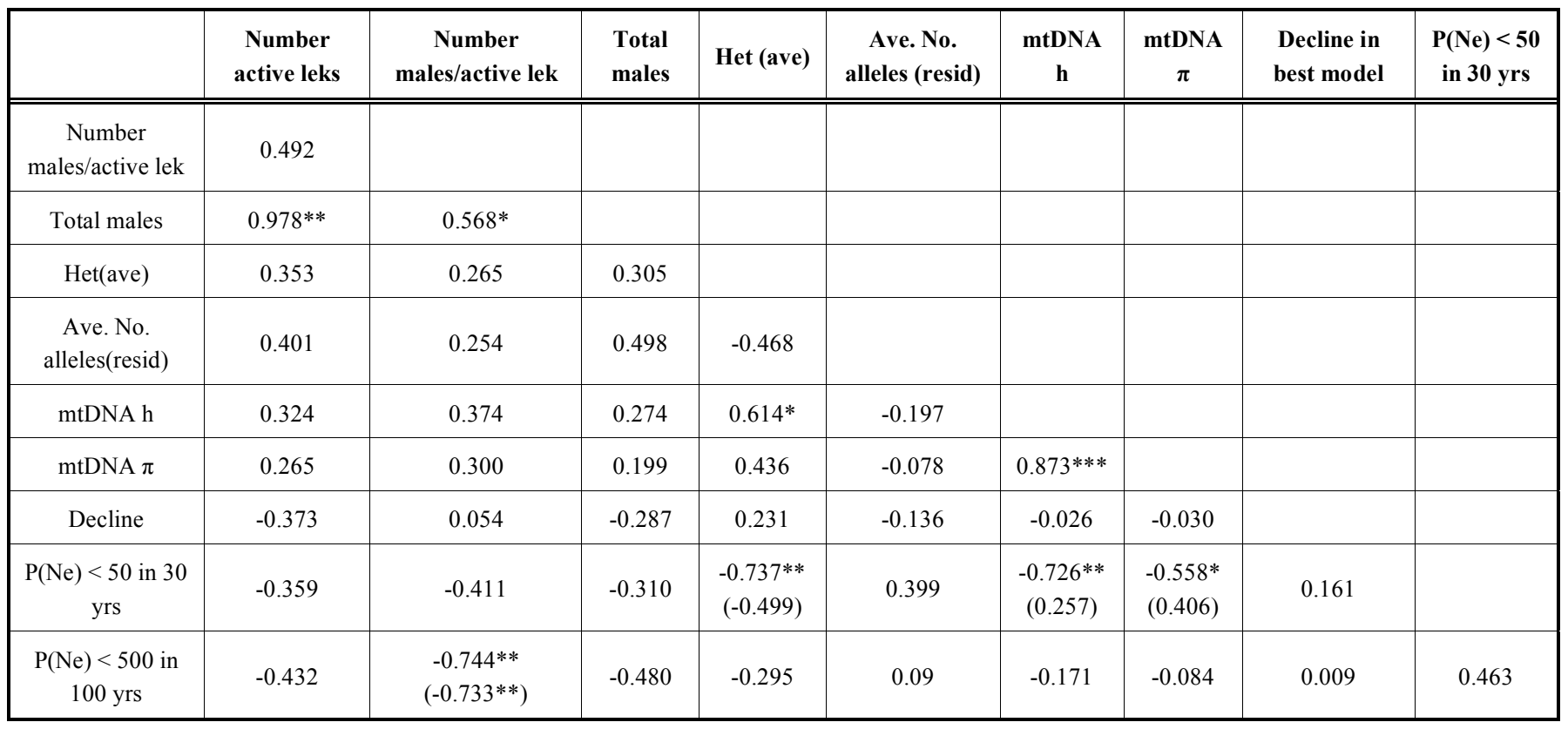
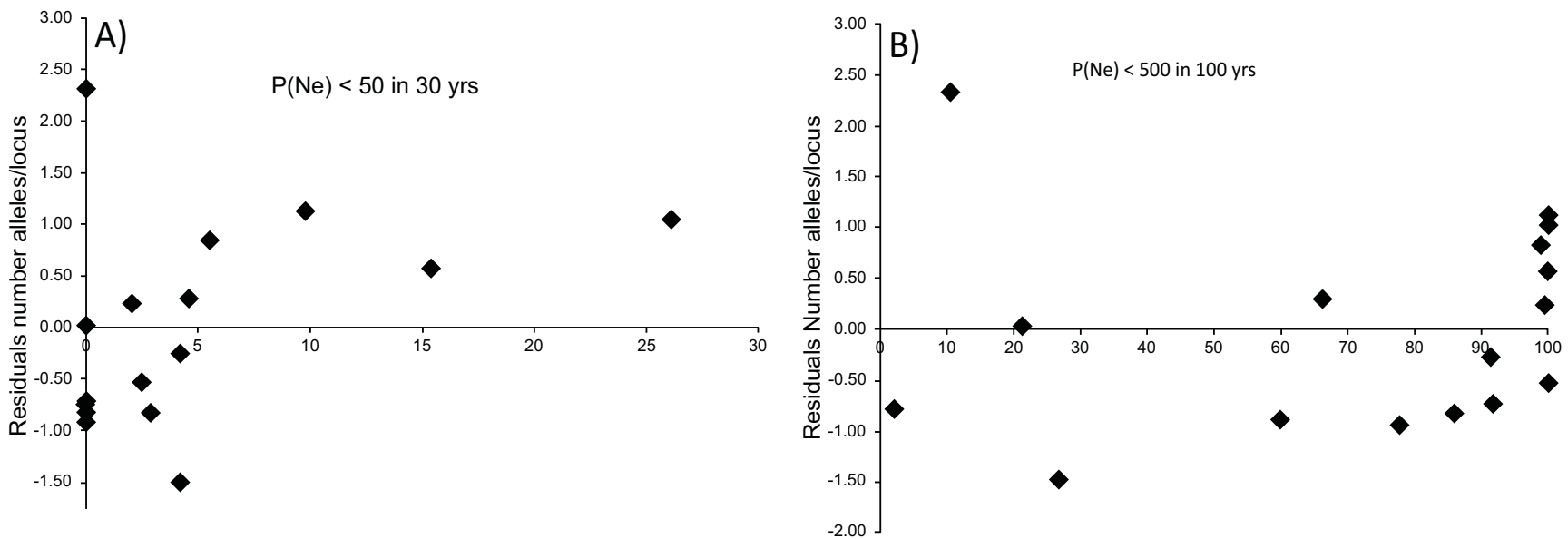

Fig. (3). A) Plot of the residual number of alleles/locus for the seven microsatellite loci [1] versus the $\mathrm{P}(\mathrm{NE})<50$ in 30 yrs [4] for the 16 population samples of greater sage-grouse, showing a lack of a relationship. B) Plot of the residual number of alleles/locus for the seven microsatellite loci [1] versus the $\mathrm{P}(\mathrm{NE})<500$ in $100 \mathrm{yrs}$ [4] for the 16 population samples of greater sage-grouse, showing a lack of a relationship.

for conservation efforts." Oyler-McCance et al. [1: p. 1308] stated that "genetic data used in conjunction with large-scale demographic and habitat data will provide an integrated approach to conservation efforts for the greater sage-grouse." This is the tact taken in this analysis.

Thousands of studies have been published that include "conservation genetics" in their key word section (Google Scholar search 16 February 2014). For the majority, there are no corresponding demographic data that can be used to compare with the genetic data. Hence, results from genetic analyses are often taken as proxies of past population demography. For example, Schmidt et al. [25] stated that lower mtDNA and microsatellite variation was associated with bottlenecked populations in the Eurasian lynx (Lynx lynx) although data on population histories consisted of verbal descriptions such as "The Scandinavian population... is believed to number up to 2000 individuals... is now large and appears to be growing rapidly." Part of the lack of quantitative data on populations stems from the difficulty in observing lynx in the field, making more easily observable species such as the greater sage-grouse better suited to obtaining quantitative estimates of population demography. In fact, the genetic analyses [1] and the demographic results [4] represent one of the most extensive opportunities to compare these logically interrelated data sets. 

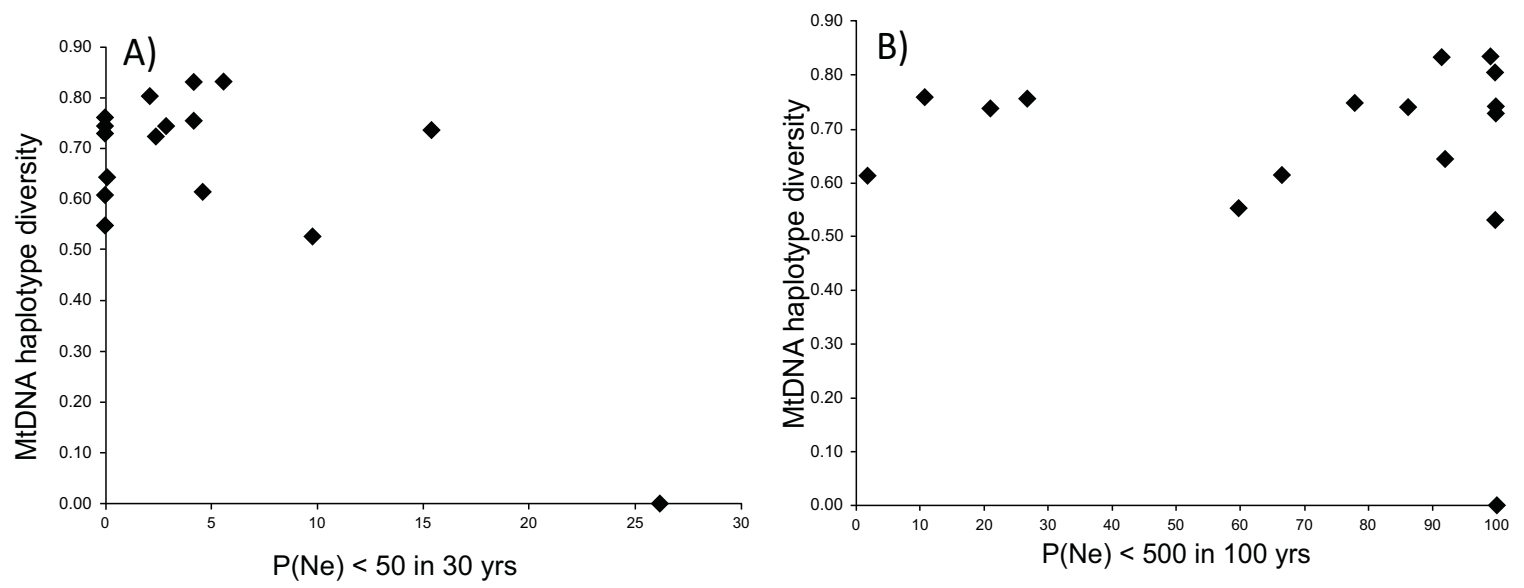

Fig. (4). A) Plot of the relationship between $\mathrm{P}(\mathrm{Ne})<50$ in 30 years [4] and mtDNA haplotype diversity [1] for greater sage-grouse, showing a lack of a relationship. B) Plot of the relationship between $\mathrm{P}(\mathrm{Ne})<500$ in 100 years and mtDNA haplotype diversity in greater sage-grouse showing a lack of a relationship.

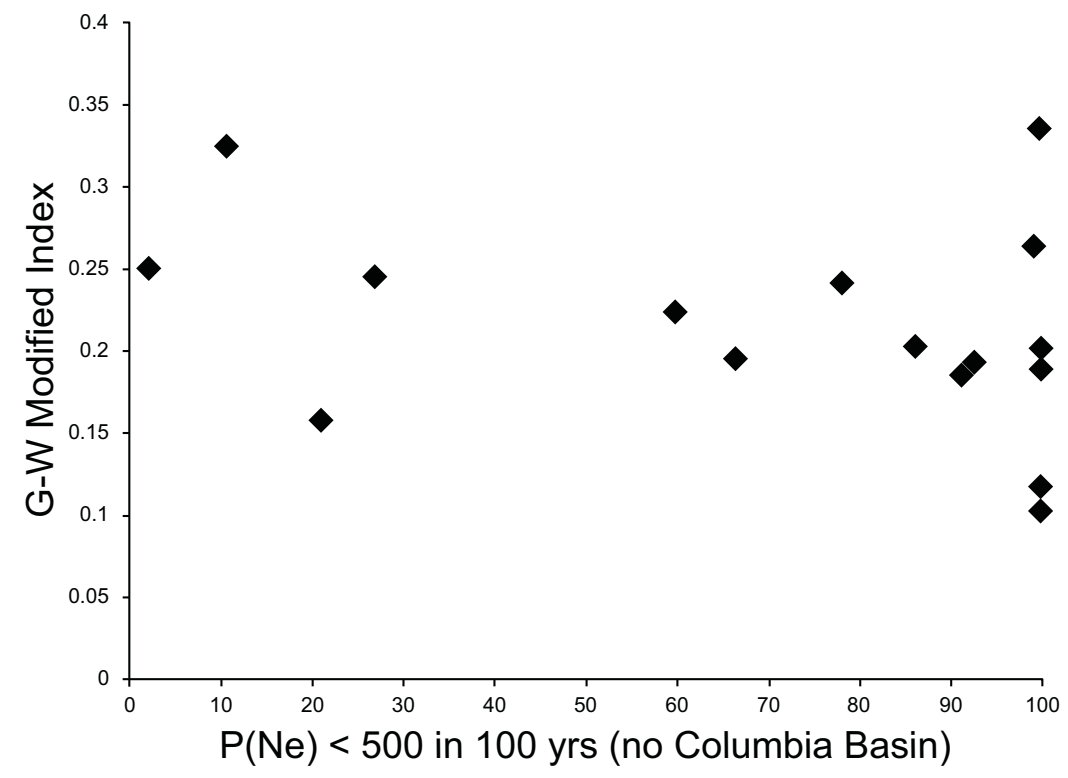

Fig. (5). Plot of the Garza-Williamson inbreeding index [7] versus $\mathrm{P}(\mathrm{Ne})<500$ in 100 years [4] excluding the Columbia Basin populations for greater sage-grouse, showing a lack of a relationship.

\section{Do Measures of Population Trends Explain Genetic Pat- terns of Variation or Reveal Inbreeding?}

Levels of genetic variability should co-vary with longterm population fluctuations. Populations in decline ought to show reductions in heterozygosity, number of alleles/locus, and nucleotide and haplotype diversity. However, it is known that heterozygosity will only show a response to demographic declines if a bottleneck is severe and long term [26], whereas the number of alleles or haplotypes per locus is more sensitive to population fluctuations.

There was no evidence that average number of alleles or haplotypes per population co-varied with estimates of population trends (16 populations) or between measures of genetic variability and number of active leks or males/active lek (45 populations). Thus, the expected population genetic signatures of differences in population size were not ob- served. Importantly, the insignificant correlation between the $\mathrm{G}-\mathrm{W}$ indices and measures of population trends suggests that populations, whether declining, increasing or stable, are not showing signs of inbreeding. This casts other studies of genetic variation alone in a different perspective, as one might not be able to infer that populations with low genetic variability are necessarily declining. In addition, Ramey et al. [27] detected several potential errors in the calculations of Garton et al. [4], although these errors would like result in less severe estimated declines and lower probabilities of populations being less than 50 or 500 in 30 or 100 years. Hence, analyses presented here potentially evaluated a "worst-case" scenario.

One clear genetic pattern is that the remaining populations in the Columbia Basin exhibit low levels of heterozygosity and numbers of alleles/locus. Although the remaining leks possess an average number of males, their isolation ap- 
parently has precluded the maintenance of genetic variability. For example, the mtDNA estimate of gene flow (Slatkin's N) averaged 15.4 among all populations excluding the two from the Columbia Basin, whereas an average of only 1.9 immigrants was exchanged between the Columbia Basin and the remaining populations. Hence, isolation from gene flow of the nature observed in Washington likely leads to reduced genetic variability and clearly poses a potential risk to population persistence. However, throughout the rest of the range, there are no similar situations, with the possibility of the population in Lyon/Mono (see below). In fact, in a small population in Alberta, Bush et al. [28: p. 343] remarked: "Although the species is endangered in Alberta and occurs in fragmented habitat, it has maintained genetic diversity and connectivity." This was explained as a result of successful dispersal of breeding individuals among leks. Given this level of connectivity at the northern fringe of the current range, it stands to reason that at least this much dispersal and gene flow exists in southern and more continuous portions of the range. It is possible that the lack of a relationship between estimated degree of population decline and levels of genetic variability is that there is still sufficient inter-area dispersal to counteract local population declines and genetic drift.

Populations with high probabilities of $\mathrm{P}(\mathrm{Ne})<50$ or 500 were already on a historically decreasing population trajectory, given that these calculations were based on lek counts over the past several decades. Possible reasons for a lack of expected genetic signatures of such declines include a high level of gene flow or an inability of available genetic measures to capture population declines owing to a lag effect e.g., [29]. For example, although the Iberian lynx (Lynx pardinus) has decreased from a total population of 1100 individuals in the 1980 s to 100 individuals distributed in two isolated populations today, Casas-Marce et al. [2] were unable to show genetic effects of bottlenecks in a sample of 36 polymorphic microsatellite loci. However, in randomly sampling from the 1181 individuals for which microsatellite data were available, there are strongly reduced levels of alleles/locus in population samples identical in size to those analyzed in this study (Zink, unpubl. data). Thus, the lack of a relationship between genetic and $\mathrm{P}(\mathrm{Ne}<50,500)$ in greater sage-grouse is likely not an artifact of the sensitivity of the genetic markers compared.

\section{Evolutionary History of Greater Sage-Grouse}

An understanding of the past evolutionary history of a species can provide useful perspective on current populations and their distributions, and how the species might respond to future climate change scenarios. The two historically divergent mtDNA lineages (Clades I and II) might have originally corresponded to small-bodied (Clade I) and largebodied (Clade II) birds. If these two clades had always been part of an interbreeding population, there should not be genetic differences between two clades from the same mtDNA gene genealogy. Based on differences in mismatch distributions (Fig. 7) and associated estimates of variability, these two clades likely represent once geographically and genetically independent lineages that retained the ability to interbreed. In my opinion there is no relevant calibration for a short section of mtDNA control region to determine the age at which these two clades last shared a common ancestor, but the degree of divergence (ca. $15 \%$ ) is consistent with a Late Pleistocene, if not earlier, origin [30]. Niche models suggest a refugium for Clade II individuals in the southeastern portion of the range, and it would appear that these two clades were isolated as recently as the Last Glacial Maximum (Fig. 6). Post-glacial range expansion resulted in a pattern where members of each historical clade are now co-mingled over much of their range [1], owing to a northward spread of Clade II individuals, and an eastern expansion of clade I individuals. However, the low frequency of individuals bearing Clade I haplotypes in the northeastern part of the range (eastern Montana, Dakotas, northeastern Colorado) could mean that demographic equilibrium has not yet been reached. Alternatively, there could be an as yet unidentified adaptive reason for the nonrandom spatial distribution of haplotypes. Lastly, the potentially isolated refuge for Clade II individuals (Fig. 6B) might explain why current populations have relatively reduced levels of genetic variability.

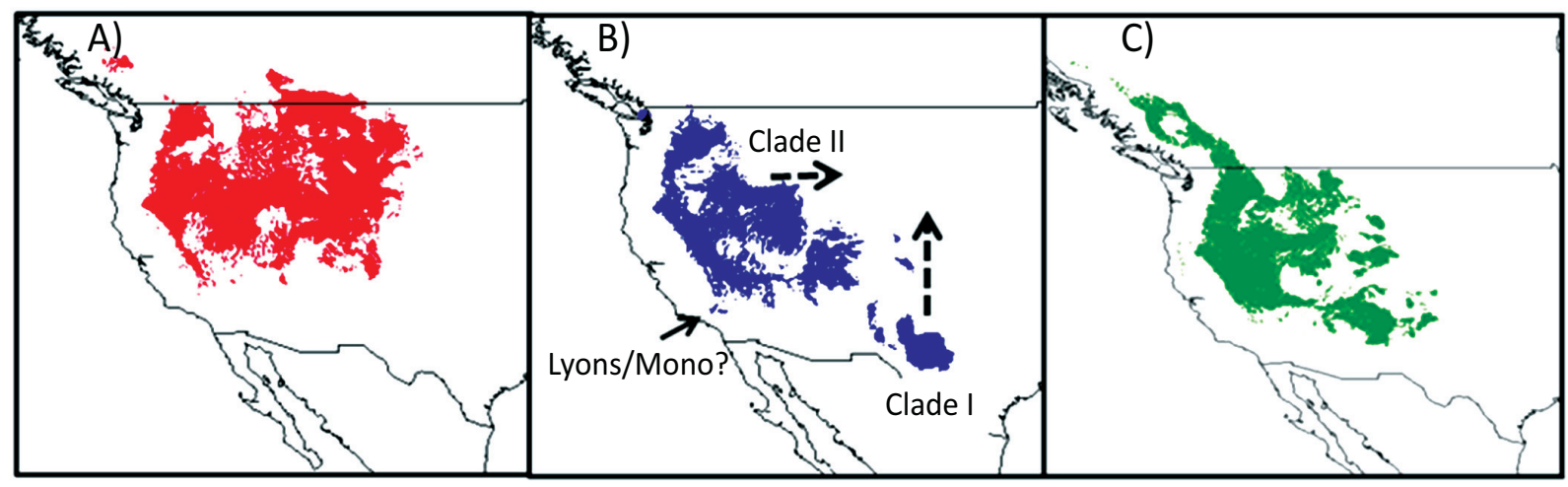

Fig. (6). Map of niche models showing predicted distributions of greater sage-grouse at the A) present and B) Last Glacial Maximum (LGM; 21,000 ybp). Blackened circles show locality points used to develop climate niche model. The arrow on the right panel indicates a possible refugium for the Lyons-Mono population that is today genetically differentiated. This distribution of Clade II could correspond to populations today considered the Gunnison sage-grouse (Centrocercus minimus). 


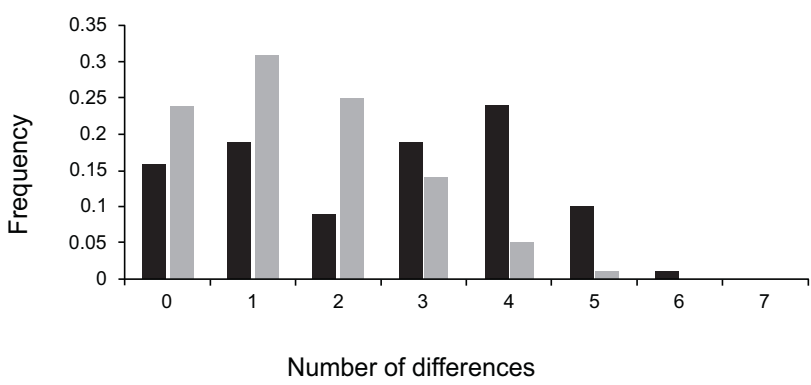

Fig. (7). Distribution of pairwise differences for Clade I (black bars) and Clade II (gray bars) mtDNA haplotypes [1]. The differing distributions suggest that the two clades of greater sage-grouse were once allopatric and had independent demographic histories until they were reunited following glacial retreat.

The projected LGM distribution (Fig. 6) indicates a southerly outpost of sage-grouse that might represent the current Lyon-Mono population. This population, which is more genetically differentiated from the rest of greater sagegrouse than greater sage-grouse is from the Gunnison sagegrouse (Centrocercus minimus), has been proposed as a distinct population segment [31]. However, despite the large number of unique alleles in the Lyon-Mono population, the level of genetic divergence is similar to that among other greater sage-grouse populations. The Lyon-Mono population has similar levels of variability relative to other populations, but not to the low extent found in the Columbia Basin populations (Tables 1, 3).

Thus, niche modeling suggests both stability (western) and range displacement (eastern) of greater sage-grouse over the past 120,000 years. They obviously survived the last glaciation and responded by shifting their ranges as climates ameliorated and associated vegetation was redistributed over western North America.

\section{Comparison of Molecular Markers}

Many authors have concluded that estimates of mtDNA variation and differentiation are insufficient to describe population variation or lineage divergence owing to stochasticity inherent in any single-locus $[32,33]$. MtDNA has been used extensively over the past two decades in phylogeography and conservation genetics, and has been complemented by surveys of nuclear loci, either microsatellites or sequencing $[34,35]$. In this study, mtDNA and microsatellites were available for the same 45 populations, and although the original authors [1] did not make explicit comparisons, it is noteworthy that the two markers gave similar estimates of levels of variation and population differentiation for data set I (Table 2) although less strongly for data set II (Table 4).

\section{CONCLUSION}

There is no clear evidence that the population genetic variability of the greater sage-grouse has been influenced by range reduction and fragmentation. The microsatellite data suggest that despite past population trends, there is no evidence of heightened inbreeding in smaller populations. Indeed, over deep evolutionary time, populations ebb and flow. Only in the case of the geographically isolated Columbia Basin populations is there a demonstrable effect of popula- tion declines and loss of genetic variability, but even in these populations there is no clear evidence of inbreeding. Because genetic variability is thought to be a proxy for population health, it does not appear that demographic declines have reached a point where genetic variation is affected in greater sage-grouse, with the exception of the Columbia Basin populations.

\section{CONFLICT OF INTEREST}

The author confirms that this article content has no conflict of interest.

\section{ACKNOWLEDGEMENTS}

I thank G. F. Barrowclough, F. K. Barker, H. VázquezMiranda, M. Wells and M. Dufort for helpful discussions. R. Ramey provided an advance copy of his manuscript.

\section{SUPPLEMENTARY MATERIALS}

Supplementary material is available on the publishers web site along with the published article.

\section{PATIENT'S CONSENT}

Declared none.

\section{REFERENCES}

[1] Oyler-McCance SJ, Taylor SE, Quinn TW. A multilocus population genetic survey of the greater sage-grouse across their range. Mole Ecol 2005; 14: 1293-310.

[2] Casas-Marce M, Soriano L, López-Bao JV, Godoy JA. Genetics at the verge of extinction: insights from the Iberian lynx. Mole Ecol 2013; 22: 5503-15.

[3] United States Fish and Wildlife Service (USFWS). Endangered and threatened wildlife and plants; 12-month findings for petitions to list the greater sage-grouse (Centrocercus urophasianus) as threatened or endangered. Fed Reg 2010; 75: 13910-4014.

[4] Garton EO, Connelly JW, Horne JS, Hagen CA, Moser A, Schroeder MA. Greater sage-grouse population dynamics and probability of persistence. Stud Avian Biol 2011; 38: 293-381.

[5] Flathe, CH, Hayward GD, Beissinger SR, Stephens PA. Minimum viable populations: is there a 'magic number' for conservation practitioners? Trends Ecol Evol 2011; 26: 307-16.

[6] Excoffier L, Lischer HEL. Arlequin suite ver 3.5: A new series of programs to perform population genetics analyses under Linux and Windows. Mole Ecol Res 2010; 10: 564-7.

[7] Garza JC, Williamson EG. Detection of reduction in population size using data from microsatellite loci. Mol Ecol 2001; 10: 305-18.

[8] Rice WR. Analyzing tables of statistical tests. Evolution 1989; 43: 223-5.

[9] Moran MD. Arguments for rejecting the sequential Bonferroni in ecological studies. Oikos 2003; 100(2): 403-5.

[10] Narum SR. Beyond Bonferroni: less conservative analyses for conservation genetics. Cons Gen 2006; 7: 783-7.

[11] Kahn NW, Braun CE, Young JR, Wood S, Mata DR, Quinn TW. Molecular analysis of genetic variation among large- and smallbodied sage-grouse using mitochondrial control-region sequences. Auk 1999: 116; 819-24.

[12] Benedict NG, Oyler-McCance SJ, Taylor SE, Braun CE, Quinn TW. Evaluation of the eastern (Centrocercus urophasianus urophasianus) and western (Centrocercus urophasianus phaois) subspecies of sage-grouse using mitochondrial control-region sequence data. Cons Gen 2003; 4: 301-10.

[13] Peterson AT. Predicting species' geographic distributions based on ecological niche modeling. Condor 2001; 103: 599-605.

[14] Elith J, Phillips SJ, Hastie T, Dudík M, Chee YE, Yates CJ. A statistical explanation of MAXENT for ecologists. Divers Distrib 2011; 17: 43-57. 
[15] Phillips SJ, Anderson RP, Schapire RE. Maximum entropy modeling of species geographic distributions. Ecol Model 2006; 190: 231-59.

[16] Hijmans RJ, Cameron S, Parra J. WorldClim, Version 1.3. Berkeley, CA: University of California. Available at: http://biogeo.berkeley.edu/worldclim/worldclim.htm. 2005

[17] Brown, JL, Knowles LL. Spatially explicit models of dynamic histories: Examination of the genetic consequences of Pleistocene glaciation and recent climate change on the American Pika. Mole Ecol 2012; 21: 3757-75.

[18] Hijmans RJ, Guarino L, Bussink C, et al. DIVA-GIS Vsn. 7.1.7. A geographic information system for the analysis of species distribution data. Manual available at: http://www.diva-gis.org . 2004

[19] Librado P, Rozas J. DnaSP v5: A software for comprehensive analysis of DNA polymorphism data. Bioinformatics 2009; 25: 1451-2.

[20] Braun CE. Sage-grouse declines in western North America: What are the problems? Proceeding of Western Association of State Fish and Wildlife Agencies 1998; 78: 139-56.

[21] Connelly JW, Braun CE. Long-term changes in sage grouse Centrocercus urophasianus populations in western North America. Wildlife Biol 1997; 3: 229-34.

[22] Connelly JW, Knick ST, Schroeder MA. Stiver SJ. Conservation assessment of greater sage-grouse and sagebrush habitats: Report to the Western Association of Fish and Wildlife Agencies (WAFWA) 2004.

[23] Schroeder MJ, Aldridge CL, Apa AD, et al. Distribution of sagegrouse in North America. Condor 2004; 106: 363-76.

[24] Oyler-McCance SJ, Quinn TW. Molecular insights into the biology of greater sage-grouse. Stud Avian Biol 2011; 38: 85-94.

[25] Schmidt K, Ratkiewicz M, Konopiński MK. The importance of genetic variability and population differentiation in the Eurasian lynx Lynx lynx for conservation, in the context of habitat and climate change. Mamm Rev 2011; 41: 112-24.

[26] Nei M, Maruyama T, Chakraborty R. The bottleneck effect and genetic variability in populations. Evolution 1975; 29: 1-10.

[27] Ramey RR, Wehausen JD, Brown LM. Peer review and information quality breakdown in an endangered species act decision: The case of the greater sage grouse. Regula Sci and Technol (in press).

[28] Bush, KL, Aldridge CL, Carpenter, JE, Paszkowski CA, Boyce MS, Coltman DW. Birds of a feather do not always lek together: Genetic diversity and kinship structure of greater sage-grouse (Centrocercus urophasianus) in Alberta. Auk 2010; 127: 343-53.

[29] Barrowclough GF, Zink RM. Funds enough and time: mtDNA, nuDNA and the discovery of divergence. Mole Ecol 2009; 18 : 2934-6.

[30] Klicka J, Zink RM. The importance of recent ice ages in speciation: A failed paradigm. Science 1997; 277: 1666-9.

[31] United States Fish and Wildlife Service (USFWS). Endangered and threatened wildlife and plants; threatened status for the bi-state distinct population segment of greater sage-grouse with special rule. Fed Reg 2013; 78: 64358-84.

[32] Ballard JWO, Whitlock MC. The incomplete natural history of mitochondria. Mole Ecol 2004; 13: 729-44.

[33] Galtier N, Nabholz B, Glemin S, Hurst GDD. Mitochondrial DNA as a marker of molecular diversity: A reappraisal. Mole Ecol 2009; 18: 4541-50.

[34] Zink RM, Barrowclough GF. Mitochondrial DNA under siege in avian phylogeography. Mole Ecol 2008; 17: 2107-21.

[35] Zink RM. Drawbacks with the use of microsatellites in phylogeography: The song sparrow (Melospiza melodia) as a case study. J Avian Bio 2010; 41: 1-7.

(C) Robert M. Zink; Licensee Bentham Open.

This is an open access article licensed under the terms of the Creative Commons Attribution Non-Commercial License (http://creativecommons.org/licenses/by-nc/3.0/) which permits unrestricted, non-commercial use, distribution and reproduction in any medium, provided the work is properly cited. 